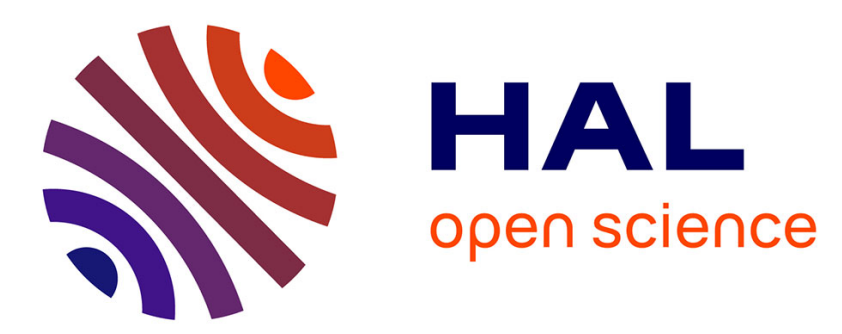

\title{
Anisotropy of wood vibrational properties: dependence on grain angle and review of literature data
}

\author{
Iris Brémaud, Joseph Gril, Bernard Thibaut
}

\section{To cite this version:}

Iris Brémaud, Joseph Gril, Bernard Thibaut. Anisotropy of wood vibrational properties: dependence on grain angle and review of literature data. Wood Science and Technology, 2011, 45 (4), pp.735-754. 10.1007/s00226-010-0393-8 . hal-00804242

\section{HAL Id: hal-00804242 \\ https://hal.science/hal-00804242}

Submitted on 25 May 2016

HAL is a multi-disciplinary open access archive for the deposit and dissemination of scientific research documents, whether they are published or not. The documents may come from teaching and research institutions in France or abroad, or from public or private research centers.
L'archive ouverte pluridisciplinaire HAL, est destinée au dépôt et à la diffusion de documents scientifiques de niveau recherche, publiés ou non, émanant des établissements d'enseignement et de recherche français ou étrangers, des laboratoires publics ou privés. 


\title{
Anisotropy of wood vibrational properties: dependence on grain angle and review of literature data
}

\author{
Iris Brémaud · Joseph Gril • Bernard Thibaut
}

\begin{abstract}
The anisotropy of vibrational properties influences the acoustic behaviour of wooden pieces and their dependence on grain angle (GA). As most pieces of wood include some GA, either for technological reasons or due to grain deviations inside trunks, predicting its repercussions would be useful. This paper aims at evaluating the variability in the anisotropy of wood vibrational properties and analysing resulting trends as a function of orientation. GA dependence is described by a model based on transformation formulas applied to complex compliances, and literature data on anisotropic vibrational properties are reviewed. Ranges of variability, as well as representative sets of viscoelastic anisotropic parameters, are defined for mean hardwoods and softwoods and for contrasted wood types. GAdependence calculations are in close agreement with published experimental results and allow comparing the sensitivity of different woods to GA. Calculated trends in damping coefficient $(\tan \delta)$ and in specific modulus of elasticity $\left(E^{\prime} / \rho\right)$ allow reconstructing the general $\tan \delta-E^{\prime} / \rho$ statistical relationships previously reported. Trends for woods with different mechanical parameters merge into a single curve if anisotropic ratios (both elastic and of damping) are correlated between them, and with axial properties, as is indicated by the collected data. On the other hand, varying damping coefficient independently results in parallel curves, which coincide
\end{abstract}

\section{Brémaud $(\bowtie) \cdot$ J. Gril}

Laboratoire de Mécanique et Génie Civil, Université Montpellier 2, CNRS,

CC048, pl. E. Bataillon, 34095 Montpellier, Cedex 5, France

e-mail: iris_bremaud@hotmail.com

\section{Brémaud}

Laboratory of Forest Resources Circulatory System,

Graduate School of Life and Environmental Sciences,

Kyoto Prefectural University, Kyoto 606-8522, Japan

B. Thibaut

CNRS- UMR Ecologie des Forêts de Guyane, Kourou, French Guyana, France 
with observations on chemically modified woods, either "artificially", or by natural extractives.

\section{Introduction}

Wood, with its cellular structure and its fibre-matrix composite cell-wall material, is highly anisotropic. As a result, the actual orientation of "grain" (usually defined as the orientation of all axial cellular elements) inside a wood piece will have strong repercussions on its apparent mechanical properties (e.g. Bodig and Jayne 1982). Although wood is most often used in longitudinal direction, most pieces of wood actually include some grain angle (GA). Even in straight-grained trees, GA occurs in sawn wood as a technical drawback of trunks not being truly cylindrical. Moreover, grain is seldom perfectly straight inside trees, and more often than not some grain deviations are present, either spiral grain which is common among softwoods and some hardwoods, or more complex patterns such as interlocked grain frequently found in tropical hardwoods, or wavy grain (e.g. Harris 1989).

In addition to GA dependence, the anisotropy of viscoelastic vibrational properties, i.e. of specific dynamic Young's $\left(E^{\prime} / \rho\right)$ and shear $\left(G^{\prime} / \rho\right)$ moduli and damping coefficients $(\tan \delta)$, also determines the vibration modes' patterns of plates (Caldersmith and Freeman 1990; Haines 2000), and the frequency response in bending vibrations. The ratios between longitudinal and shear moduli and damping coefficients are in good part responsible for the apparent frequency dependence in the range of about $1-5-10 \mathrm{kHz}$, i.e. a diminution of $E^{\prime} / \rho$ and an augmentation of $\tan \delta$, which also plays a role in the "timbre" for application in musical instruments (Ono 1996; Aizawa 1998; Haines 2000; Obataya et al. 2000).

The variability in anisotropy of vibrational properties will thus influence both their GA dependence, and the "acoustical" response of wooden pieces. However, this variability is not very well known, and information is much scattered. Amongst possible sources of variation, the mean microfibril angle is recognised as the main factor affecting both axial $E^{\prime} / \rho$ and $\tan \delta$, and their axial-to-shear anisotropy (Norimoto et al. 1986; Obataya et al. 2000). The effect of microfibril angle on $\tan \delta$ and $E^{\prime} / \rho$ results in this two properties being correlated, and the relation is similar to the case of GA effect (Ono and Norimoto 1983, 1984, 1985). The effect of cellular organisation on damping coefficients is not clear, as the above relationships are similar for softwoods and hardwoods with either diffuse- or ring-porous structure. Yet, radial $\tan \delta$ depends on the percentage of rays (Yano and Yamada 1985), and the ratio between tangential and radial $\tan \delta$ diminishes with increasing density, indicating some effect of porosity (Aoki and Yamada 1972). On the other hand, vibrational properties are very sensitive to chemical variations and/or modifications within the cell wall, which can also modulate their anisotropy (Obataya et al. 2000). Some extractives naturally present in wood can modify damping by as much as a factor of 2 and can have smaller but anisotropic effects on moduli (Brémaud et al. 2010b; Minato et al. 2010; Yano et al. 1995).

As apparent behaviour will depend on both intrinsic wood properties and potential GA inside wood pieces, it would be useful to be able to predict it. Yet, 
much less attempt has been made to describe viscoelastic dynamic properties, than static, elastic ones. Schniewind and Barrett (1972) showed that creep at different GA could be described by standard transformation formula and concluded that wood could be considered as a linear orthotropic viscoelastic material. Such formulas were also applied to GA dependence of dynamic modulus, but that of $\tan \delta$ was approached either by statistical means or simplified formulas (Ishihara et al. 1978; Ono 1983; Tonosaki et al. 1983; Yano et al. 1990).

This paper aims at gathering together the theory of GA dependence of vibrational properties, and their range of variability on different woods. GA dependence is described by a model based on transformation formula applied to complex compliances, and literature data on vibrational anisotropy are reviewed. This serves to predict the response of typical and contrasted wood types, and to interpret the relationship between damping coefficient and specific modulus.

\section{Effect of grain angle on rigidity and damping: theory}

The anisotropic organisation of wood in a trunk can be described by two systems of axis (Fig. 1): a global one aligned to the stem of the tree (and to "axial" samples taken from it), which we call $[R, T, L]$; and a local one fitting the grain's orientation, here noted $[1,2,3]$. When the trunk is closely cylindrical and no source of fibre deviation is considered, it can be assumed that both systems of axis, $[1,2,3]$ and $[R, T, L]$, coincide. However, in a trunk exhibiting grain deviation (spiralled or interlocked), or in pieces of wood sawn out of grain, directions 2 and 3 form an angle-from a few degrees to up to $45^{\circ}$ in extreme cases-to the directions $T$ and $L$.

(a)

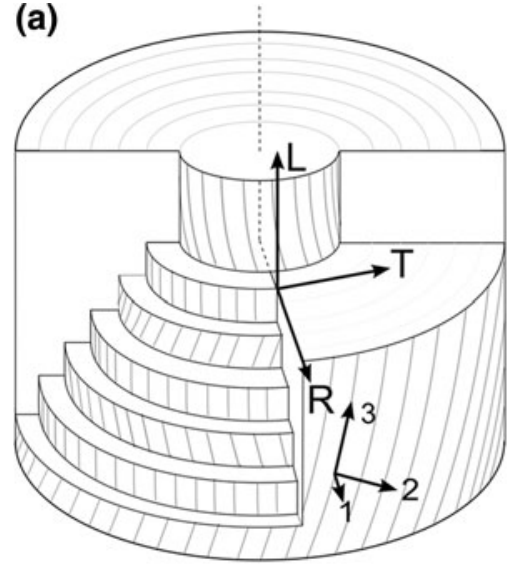

(b)

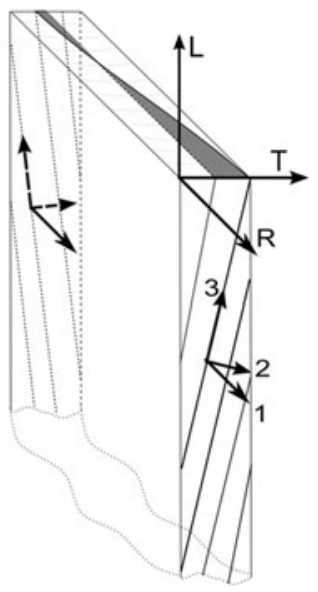

Fig. 1 Schematic view of the systems of axis related to the trunk = "global" $[R, T, L]$ and related to the grain direction $=$ "local" $[1,2,3]$. a In the particular case of interlocked grain within a trunk; $\mathbf{b}$ within a quarter-cut piece of wood cut along the stem axis: either a narrow (1-3 cm wide) board with interlocked grain, or a wide $(>10-20 \mathrm{~cm})$ plank with spiral grain 
Mechanical properties in the global system of axis can be calculated from those in the local system, as a function of the angle $(\theta)$ of grain with respect to the stem axis, by applying the transformation formula for elastic solids (e.g. Bodig and Jayne 1982). This gives, for the compliance along the stem axis:

$$
\begin{aligned}
S_{L L} & =S_{33} \cos ^{4} \theta+\left(S_{44}+2 S_{32}\right) \cos ^{2} \theta \sin ^{2} \theta+S_{22} \sin ^{4} \theta \\
& =\frac{S_{33}+\left(S_{44}+2 S_{32}\right) u+S_{22} u^{2}}{(1+u)^{2}}
\end{aligned}
$$

where $u=\tan ^{2} \theta$ and the component $S_{i j}$ of the compliance matrix represent the strain response in direction $i$ to stress applied in direction $j$.

In the case of linear viscoelastic solids, Eq. 1 can also be applied to the complex compliance, with each component of the compliance matrix written in the form $S_{i j}^{*}=S_{i j}^{\prime}-i S_{i j}^{\prime \prime}$, where $S_{i j}^{\prime}$ is the storage compliance and $S_{i j}^{\prime \prime}$ the loss compliance. Separating the real and imaginary part of the expression leads to:

$$
S_{L L}^{\prime}=\frac{S_{33}^{\prime}+\left(S_{44}^{\prime}+2 S_{32}^{\prime}\right) u+S_{22}^{\prime} u^{2}}{(1+u)^{2}} ; \quad S_{L L}^{\prime \prime}=\frac{S_{33}^{\prime \prime}+\left(S_{44}^{\prime \prime}+2 S_{32}^{\prime \prime}\right) u+S_{22}^{\prime \prime} u^{2}}{(1+u)^{2}}
$$

Each compliance coefficient $S_{i j}^{*}$ can be expressed by its inverse $Q_{i j}^{*}$ :

$$
Q_{i j}^{*}=\frac{1}{S_{i j}^{*}}=\frac{1}{S_{i j}^{\prime}-i S_{i j}^{\prime \prime}}=\frac{S_{i j}^{\prime}+i S_{i j}^{\prime \prime}}{S_{i j}^{\prime 2}+S_{i j}^{\prime \prime 2}} \Rightarrow\left\{\begin{array}{l}
Q_{i j}^{\prime}=\frac{S_{i j}^{\prime}}{S_{i j}^{\prime 2}+S_{i j}^{\prime \prime 2}}=\frac{1}{1+\tan \delta_{i j}^{2}} \frac{1}{S_{i j}^{\prime}} \\
Q_{i j}^{\prime \prime}=\frac{S_{i j}^{\prime \prime}}{S_{i j}^{\prime 2}+S_{i j}^{\prime \prime 2}}=\frac{1}{1+\tan \delta_{i j}^{2}} \frac{S_{i j}^{\prime \prime}}{S_{i j}^{\prime 2}}
\end{array}\right.
$$

where

$$
\tan \delta_{i j}=\frac{S_{i j}^{\prime \prime}}{S_{i j}^{\prime}}=\frac{Q_{i j}^{\prime \prime}}{Q_{i j}^{\prime}}
$$

are the damping coefficients, typically of the order of $1 \%$ in the time-temperature domain considered here for wood, so that $\left(\tan \delta_{i j}\right)^{2} \ll 1$ and:

$$
S_{i j}^{\prime} \approx S_{i j}=\sqrt{S_{i j}^{\prime 2}+S_{i j}^{\prime \prime 2}} ; \quad Q_{i j}^{\prime} \approx \frac{1}{S_{i j}^{\prime}} \approx \frac{1}{S_{i j}} ; \quad Q_{i j}^{\prime \prime} \approx \frac{S_{i j}^{\prime \prime}}{S_{i j}^{\prime 2}} \approx \frac{\tan \delta_{i j}}{S_{i j}}
$$

The $Q_{i j}$ can be expressed using engineering notations:

$$
Q_{L L}=E_{L} ; \quad Q_{33}=E_{3} ; \quad Q_{22}=E_{2} ; \quad Q_{44}=G_{32} ; \quad Q_{32}=-E_{3} / \nu_{32}
$$

where $E_{L}, E_{3}$ and $E_{2}$ are the Young's moduli along the axial direction of the tree, along the grain and across the grain (orthogonal to the radial direction), respectively, $G_{32}$ is the shear modulus in the tangential plane and $v_{32}$ the Poisson's ratio relating the strain along 2 to the strain along 3 in the case of uniaxial loading along 3 .

Then, the evolution of "apparent", global-scale storage modulus ${E^{\prime}}_{L}^{\prime}(\theta)$ and loss modulus $E_{L}^{\prime \prime}(\theta)$ can be derived as a function of grain angle and properties at local scale: 


$$
E_{L}^{\prime}(\theta) \approx E_{3} \frac{(1+u)^{2}}{1+a^{\prime} u+b^{\prime} u^{2}} ; \quad E_{L}^{\prime \prime}(\theta) \approx E_{3} \tan \delta_{33} \frac{(1+u)^{2}\left(1+a^{\prime \prime} u+b^{\prime \prime} u^{2}\right)}{\left(1+a^{\prime} u+b^{\prime} u^{2}\right)^{2}}
$$

In order to make the reading easier, dimensionless terms $a^{\prime}, a^{\prime \prime}, b^{\prime}$ and $b^{\prime \prime}$ are used:

$$
\begin{array}{rr}
a^{\prime}=\frac{S_{44}^{\prime}+2 S_{32}^{\prime}}{S_{33}^{\prime}} & b^{\prime}=\frac{S_{22}^{\prime}}{S_{33}^{\prime}} \\
a^{\prime \prime}=\frac{S_{44}^{\prime \prime}+2 S_{32}^{\prime \prime}}{S_{33}^{\prime \prime}} & b^{\prime \prime}=\frac{S_{22}^{\prime \prime}}{S_{33}^{\prime \prime}}
\end{array}
$$

From Eqs. 5 and 6:

$$
\begin{array}{ll}
a^{\prime} \approx E_{3} / G_{32}-2 v_{32} & b^{\prime} \approx E_{3} / E_{2} \\
a^{\prime \prime} \approx \frac{E_{3} / G_{32} \tan \delta_{44}-2 v_{32} \tan \delta_{32}}{\tan \delta_{33}} & b^{\prime \prime} \approx\left(E_{3} / E_{2}\right) \frac{\tan \delta_{22}}{\tan \delta_{33}}
\end{array}
$$

In the case of wood, $E_{3} / G_{32}$ is typically one order of magnitude higher than $v_{32}$, so that in the expression of $a^{\prime \prime}$ it will be convenient to isolate the contribution of shear damping.

$$
a^{\prime \prime} \approx \frac{\left(E_{3} / G_{32}-2 v_{32}\right) \tan \delta_{44}+2 v_{32}\left(\tan \delta_{44}-\tan \delta_{32}\right)}{\tan \delta_{33}}
$$

so that:

$$
a^{\prime \prime} \approx a^{\prime} \frac{\tan \delta_{44}}{\tan \delta_{33}}(1+q) \quad \text { where } \quad q=2 \frac{\tan \delta_{44}-\tan \delta_{32}}{\tan \delta_{44}} \frac{v_{32}}{a^{\prime}} ; \quad b^{\prime \prime} \approx b^{\prime} \frac{\tan \delta_{22}}{\tan \delta_{33}}
$$

It is convenient to use the specific storage modulus $\left(E^{\prime} / \rho\right)$ and specific loss modulus $\left(\mathrm{E}^{\prime \prime} / \rho\right)$, i.e. the moduli divided by specific gravity $(\rho)$, given that, on one hand the specific Young's modulus corresponds to the actual measurements by vibrational methods, on the other hand they are representative of the properties of the cell walls (Norimoto et al. 1986; Obataya et al. 2000).

From these calculations of loss and storage moduli, the grain angle dependence of their ratio, the loss (or damping) coefficient $\tan \delta$ can be obtained.

$$
\tan \delta_{L(\theta)}=\frac{E_{L(\theta)}^{\prime \prime}}{E_{L(\theta)}^{\prime}}=\frac{\left(E_{L(\theta)}^{\prime \prime} / \rho\right)}{\left(E_{L(\theta)}^{\prime} / \rho\right)}
$$

In the case of a beam made of wood layers with varying GA, it is possible to evaluate the global modulus of the beam by the application of the laminate theory, separately to the storage and loss moduli of each layer. In another paper by the authors (Brémaud et al. 2010b), this has been applied to a configuration with interlocked grain.

\section{Anisotropy of moduli and loss coefficients of woods}

In order to overcome the fact that data are relatively scarce, or in any case much scattered, concerning the anisotropy of dynamic moduli and of damping coefficients, 


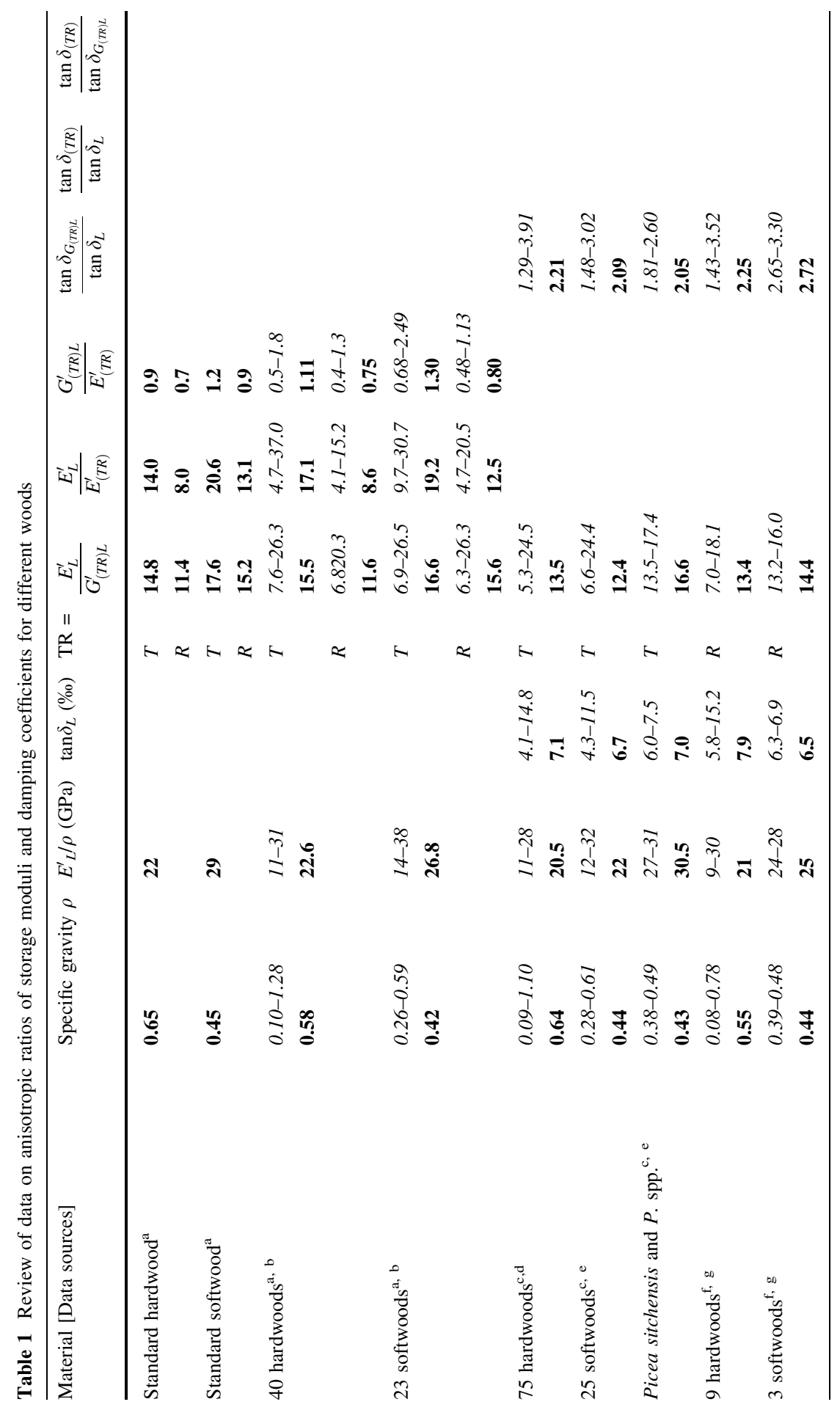




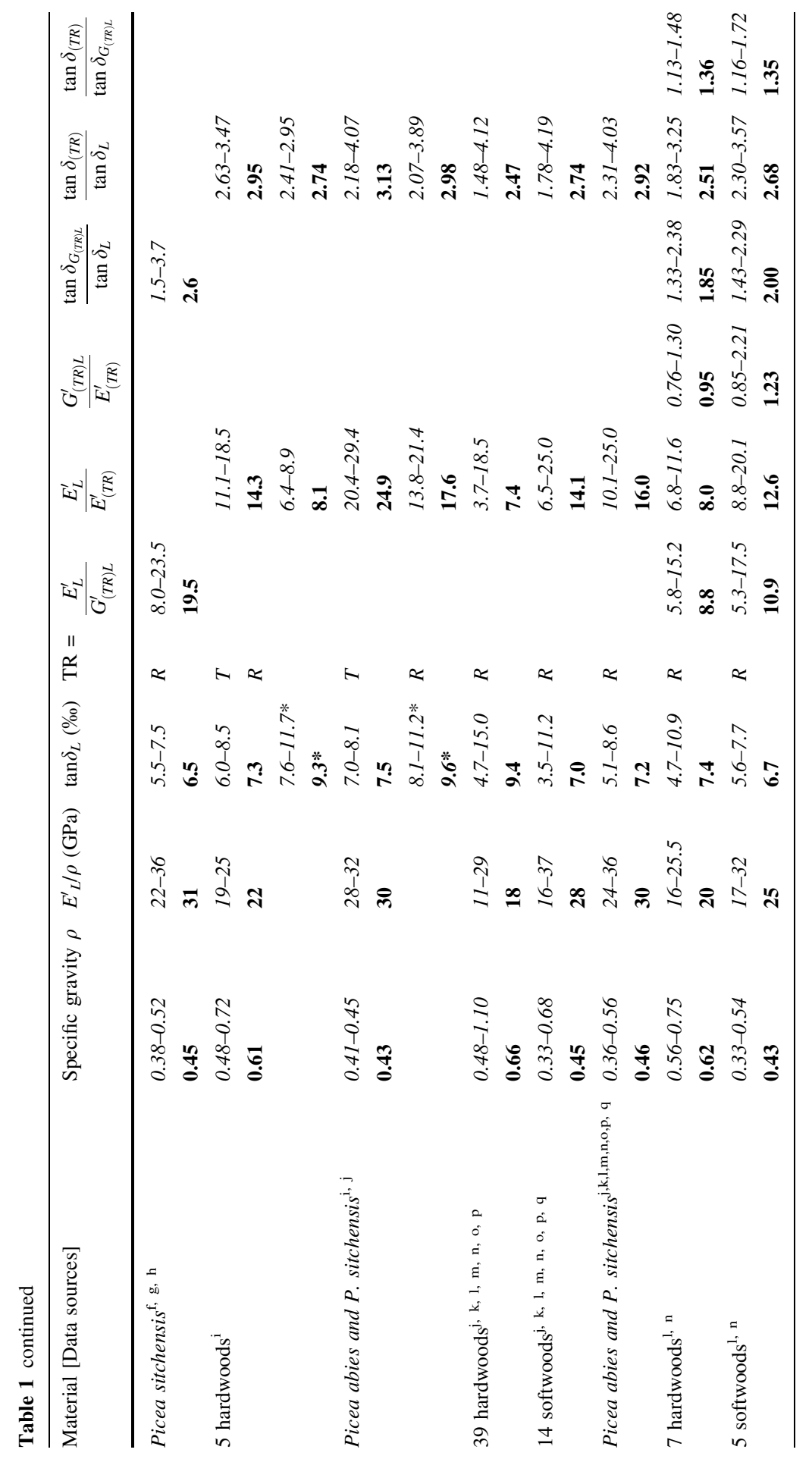




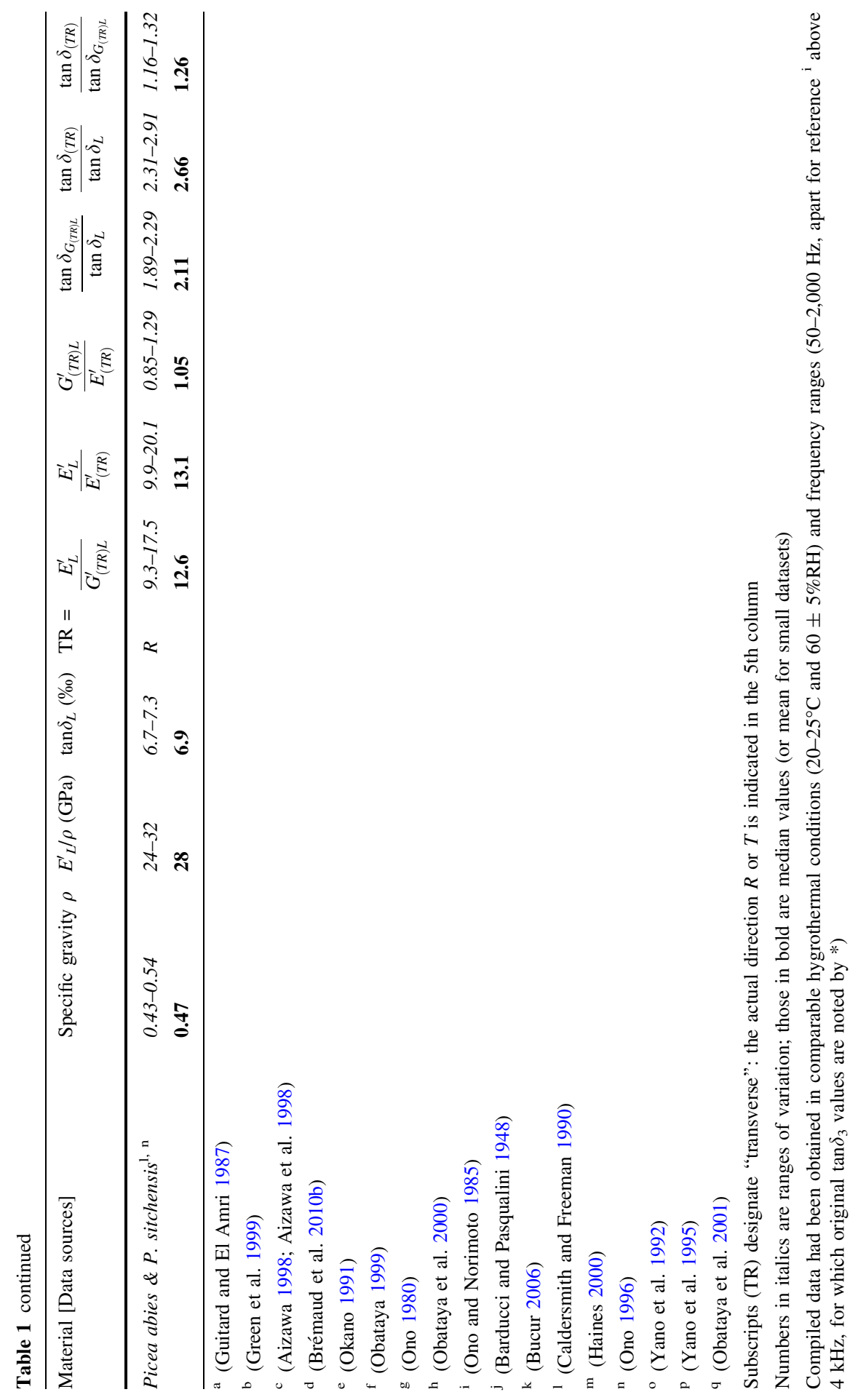


the orders of magnitude for these anisotropic ratios are summarised in Table 1, based on different samples and references. It can reasonably be assumed that values found in the literature had been obtained on straight-grained specimens where the globalscale system of axis $[R, T, L]$ and the fibre-related one $[1,2,3]$ can be superimposed.

\section{Axial-to-shear anisotropy}

For storage moduli, mean anisotropic ratios are proposed by Guitard and El Amri (1987) for "standard hardwoods" and "standard softwoods" (1st and 2nd row of Table 1, with actual ranges of variation shown in the 3 rd and 4th row). Regarding the differences between radial and tangential planes, $E_{L} / G_{T L}$ and $E_{L} / G_{R L}$ are strongly correlated ( $R^{2}$ of 0.76 for both hardwoods and softwoods). The ratio between tangential-longitudinal and radial-longitudinal shear moduli $\left(G_{T L} / G_{R L}\right)$ ranges from 0.50 to 0.98 (median 0.74 ) for hardwoods, and from 0.72 to 1.33 (median 0.95) for softwoods (Guitard and El Amri 1987; Green et al. 1999).

Data on the axial-to-shear anisotropy of damping coefficients originate mostly from experiments both in flexural and in torsional vibration. They cover a wider range of species for the axial-tangential plane $\left(\tan \delta_{G T L} / \tan \delta_{L}\right.$ for 75 hardwood and 25 softwood species, 5th, 6th and 7th rows of Table 1) than for the axial-radial one (rows 8, 9 and 10 in Table 1). Data on both $\tan \delta_{G R L}$ and $\tan \delta_{G L T}$ obtained on a single sampling are not known; however, comparison on the same species across different studies suggests that they are not very different (average $\tan \delta_{G L T} / \tan \delta_{G R L}$ of 1.04 on 6 hardwoods, of 0.95 on 5 softwoods).

Axial-to-shear anisotropic ratios are very weakly (for storage moduli) or not (for $\tan \delta$ ) related to specific gravity (Table 2 for data in the $L-T$ plane, similar observations can be made for the $L-R$ plane). But they are strongly related to mechanical properties along the grain, which denotes that axial-to-shear anisotropy is primarily determined by cell-wall properties, notably by the mean microfibril angle (Obataya et al. 2000). However, cellular structure can also have an effect, as $\tan \delta_{G R L}$ depends on the percentage of rays for hardwoods (Yano and Yamada 1985). The axial-to-shear anisotropy ratio in damping coefficients is strongly correlated to that in storage moduli, as reported by Aizawa et al. (1998), Obataya (1999) and Obataya et al. (2000). The relationship between $\tan \delta_{G T L} / \tan \delta_{L}$ and $E_{L}^{\prime} / G^{\prime}{ }_{T L}$ is nearly the same for softwoods and hardwoods, although there is more dispersion for the latter.

Table 2 Pearson's correlation coefficients between specific gravity $(\rho)$, axial properties, and axial-to-shear $(L-T$ plane) anisotropy ratios

Upper diagonal: softwoods, lower diagonal: hardwoods. Based on the data from references ${ }^{\mathrm{a}, \mathrm{b}, \mathrm{c}, \mathrm{e}, \mathrm{m}}$ in Table 1

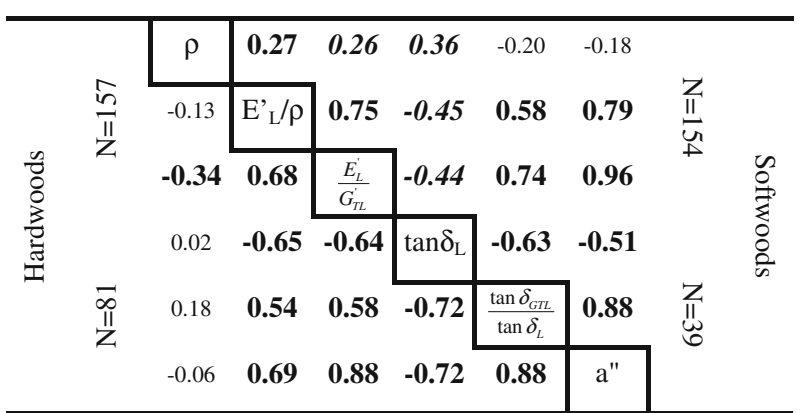


Such correlations between the anisotropy in moduli and that in damping should be taken into account for further analysis. Thus, in order to get a general view, mean values of all parameters will be used, but for woods with very different elastic anisotropy (correlated to $E_{L}^{\prime} / \rho$ values), loss anisotropic ratios will have to be adjusted, for example for "resonance" spruce wood (mostly Picea abies and P. sitchensis), which is highly anisotropic (Obataya et al. 2000).

\section{Axial-to-transverse anisotropy}

As for shear, average axial-to-transverse (radial and tangential) anisotropic ratios of elastic (storage) moduli were proposed for "standard" hardwoods and softwoods (1st and 2nd rows of Table 1 with ranges of variations in 3rd and 4th rows) according to Guitard and El Amri (1987) and Green et al. (1999). Anisotropy covers a wide range of hardwoods, from the lowest values of "curly maple" (due to systematic grain deviation and radial reinforcement by rays, Bucur 2006) to the highest ratios for balsa. In the case of hardwoods, there is a strong correlation $(R=0.90)$ between $E_{L}^{\prime} / E_{R}^{\prime}$ and $E_{L}^{\prime} / E^{\prime}{ }_{T}$ and both ratios diminish with increasing specific gravity, whereas for softwoods they are nearly independent of density and more weakly linked between them.

For transverse damping coefficients, the majority of existing data concerns the radial direction, while there is little information on the tangential one. However, $\tan \delta_{T}$ is quite strongly correlated to $\tan \delta_{R}$ ( $R=0.87$ on 14 hardwoods), which may be useful to get approximations of $\tan \delta_{T}$. The $\tan \delta_{T} / \tan \delta_{R}$ ratio diminishes with increasing specific gravity, and ranges from 1.01 to 1.36 (mean 1.14) on 14 hardwoods. This range is comparable to the one on 4 softwoods, and the mean $\tan \delta_{T} / \tan \delta_{R}$ is about 1.05 for spruces. These relations are based on a moderate number of species, but are consistent over three different studies (Aoki and Yamada 1972; Barducci and Pasqualini 1948; Ono and Norimoto 1985) and they sound realistic, as the corresponding ratio $E_{R}^{\prime} / E^{\prime}{ }_{T}$ is comparable with the average on more numerous species: 1.66 and 1.51 for hardwoods and softwoods, respectively.

Actual data on axial-to-tangential anisotropy of $\tan \delta$ are listed in Table 1 (11th and 12 th rows for 5 hardwoods and 2 spruces). The axial-to-radial ratio $\left(\tan \delta_{R} /\right.$ $\tan \delta_{L}$ ) ranges from 1.49 to 4.12 (median 2.47 ) over 39 hardwoods species and from 1.78 to 4.19 (median 2.74) over 14 softwood species (Table 1 from row 11 to the end).

The axial-radial anisotropy in damping coefficient is correlated to that in storage moduli and to axial properties (Table 3). However, most relations are less strong than in the case of shear anisotropy, which may denote a bigger importance of cellular organisation when compared to cell-wall properties.

\section{Poisson's ratio}

Elastic/storage Poisson's ratio $v_{L T}^{\prime}$ ranges from 0.31 to 0.73 on hardwoods, and from 0.36 to 0.6 on softwoods, with respective "standard" values of 0.46 and 0.43 (Guitard and El Amri 1987; Green et al. 1999). 
Table 3 Pearson's correlation coefficients between specific gravity, axial properties, and axial-to-radial anisotropy ratios

Upper diagonal: softwoods, lower diagonal: hardwoods. Based on data from references $\mathrm{a}, \mathrm{b}, \mathrm{j}, \mathrm{k}, \mathrm{l}, \mathrm{m}, \mathrm{n}, \mathrm{o}, \mathrm{p}, \mathrm{q}$ in Table 1

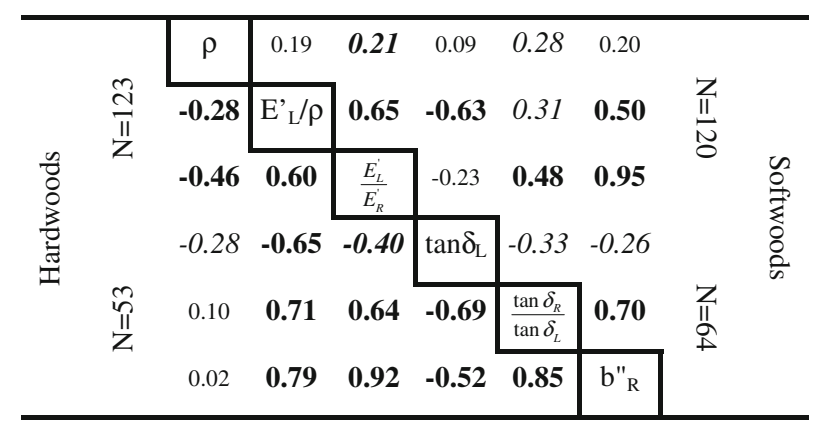

Experimental values of Poisson's loss factor for wood in a time-temperature domain close to audible frequencies and c. $20^{\circ} \mathrm{C}$ are not known. For isotropic materials, it would be about one decade smaller than shear-loss coefficient (Pritz 2007), but this is not necessarily true for anisotropic cellular materials. According to Eq. 11 , the term $q$ would tend towards zero if $\tan \delta_{32}$ (Poisson's loss factor) was close to $\tan \delta_{44}$ (in shear). If $\tan \delta_{32}$ was negligible compared to $\tan \delta_{44}$, the term $q$ would contribute about up to $10 \%$ to the term $a^{\prime \prime}$ used for calculations.

Variability and relative influence of axial-to-shear and axial-to-transverse parameters

Over all the collected data on both hardwoods and softwoods species, the axial-toshear anisotropy ranged from 4 to 30 (mean 14) for $E_{3}^{\prime} / G_{23}^{\prime}$ and from 1.3 to 3.9 (mean 2.25) for $\tan \delta_{44} / \tan \delta_{33}$ (from now on, it is admitted that values that are listed in Table 1 in the $[R, T, L]$ system of axis are equivalent to those in the $[1,2,3]$ system of axis). The axial-to-tangential anisotropy ranged from 5 to 40 (mean 18) for $E_{3}^{\prime} / E_{2}^{\prime}$ and from 1.6 to 4.4 (mean 2.9) for $\tan \delta_{22} / \tan \delta_{33}$ (based on both actual tangential data and estimates from radial ones). Ranges for hardwoods and softwoods are resumed in Table 4.

For moderate GA (up to $20-25^{\circ}$ ), the total variability in shear anisotropy accounted for most of the differences in GA dependence of storage modulus (Fig. 2a), while the full variability in tangential anisotropy also contributed significantly to damping coefficient (Fig. 2b). Over the whole range of GA, $L / G_{T L}$ anisotropy still contributed the most important (quantitatively) to the variability in GA dependence for $E^{\prime}$, while $L / T$ anisotropy contributed at least as much to the GA dependence of $\tan \delta$.

\section{Grain angle dependence of vibrational properties for different types of woods}

In order to illustrate (Fig. 3) the grain angle dependence of dynamic mechanical properties for different wood types, average values for hardwoods and softwoods were defined (Table 4). Mechanical parameters are also summarised for the highly anisotropic "resonance" spruces and for a species (African padauk) with 


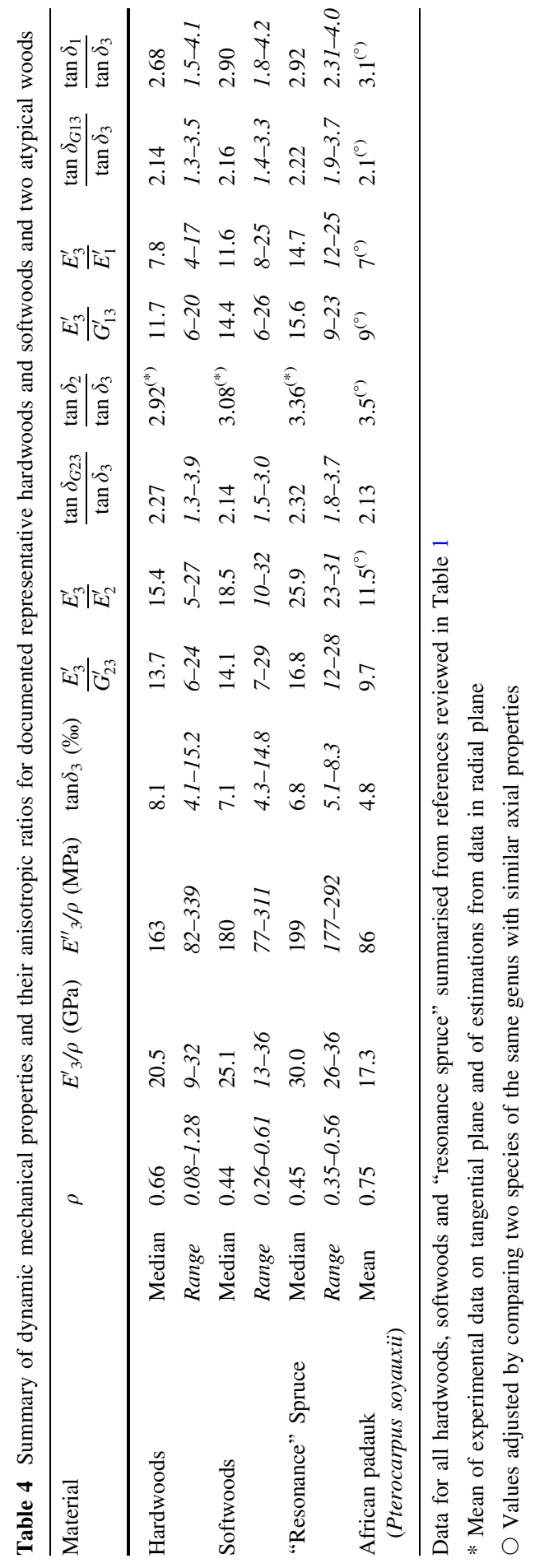



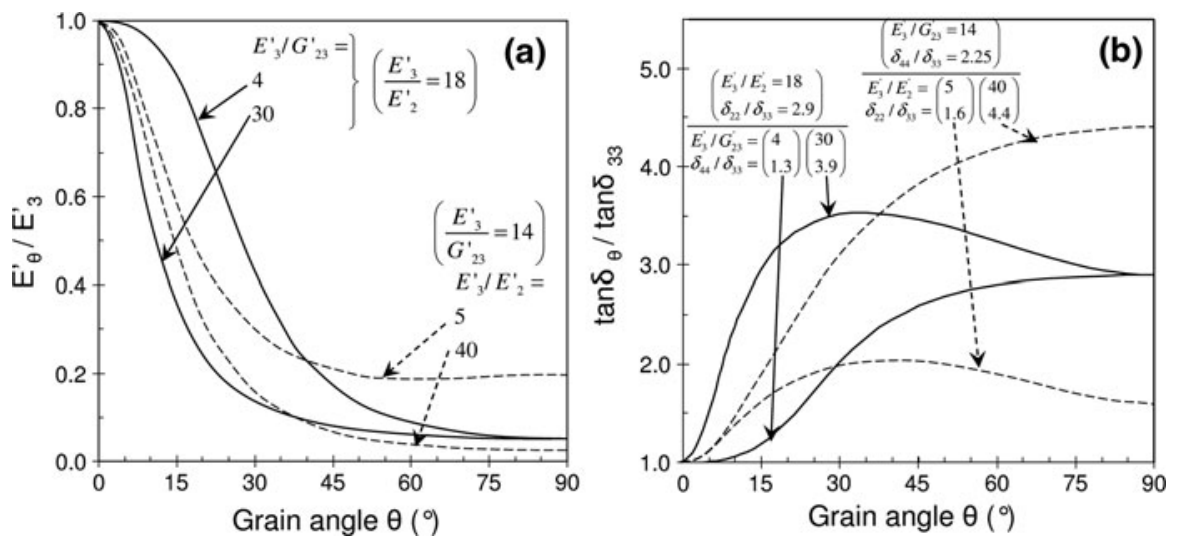

Fig. 2 Relative influence of the anisotropy ratios (longitudinal to shear, and longitudinal to tangential) on the grain-angle dependence of (a) dynamic Young's modulus and (b) loss factor. Plain curves: full range of variation in axial-to-shear anisotropy ratios with axial-tangential ones fixed at their mean values; dashed curves: full range of variation in $3-2$ ratios with $3-\mathrm{G}_{23}$ ratios fixed at their mean values

abnormally low damping coefficient and reduced anisotropy (Brémaud et al. 2010b).

The relationship between elastic anisotropy and specific Young's modulus along the grain is clearly visible in the grain angle dependence of $E^{\prime} / \rho$ for different wood types (Fig. 3a): for a small GA of $5^{\circ}, E^{\prime} / \rho$ decreases of $11 \%$ (when compared to $0^{\circ}$ GA) for spruce, but only of $5 \%$ for padauk. This has non-negligible practical repercussions, as GA of a few degrees are common in sawn pieces of wood; $5-10^{\circ}$ can quite easily occur in softwood planks, and about $10-15^{\circ}$ are not uncommon in hardwoods with grain deviations. For a GA of only $7^{\circ}$, "resonance" qualities of spruce become equivalent to the average softwoods along the grain. The GA dependence curves of spruce and mean softwoods join up for an angle $\geq 15^{\circ}$, those of mean hardwoods and of padauk for $\mathrm{GA} \geq 10^{\circ}$. For angles bigger than $20^{\circ}$, the tendencies are comparable for all wood types represented.

The scheme of GA dependence is quite different for specific loss modulus $E^{\prime \prime} / \rho$ which remains quite stable for moderate GA of up to $10-15^{\circ}$, or even slightly increases (Fig. 3b). This denotes the fact that, over small angles, the damping coefficient increases a bit faster than Young's modulus decreases. Wood types compare differently than in the case of $E^{\prime} / \rho$ : GA dependence of mean hardwoods and softwoods is very similar, and "resonance" spruce is less different in terms of specific loss modulus, while padauk wood is here the most atypical one. The latter is also noticeable for its systematically lower damping coefficient $\tan \delta$ over varying GA (Fig. 3c). The damping coefficient of mean hardwoods and softwoods increases according to grain angle in a nearly parallel way, and the trend for "resonance" spruce starts to be dissociated from that for mean softwoods for GA $\geq 10^{\circ}$.

The calculated trends in GA dependence for $\tan \delta$ and $E^{\prime} / \rho$ result in relationships between these properties (Fig. 3d) quite similar to those reported by Ono and Norimoto $(1983,1984,1985)$; this will be discussed below. Such relationships are 

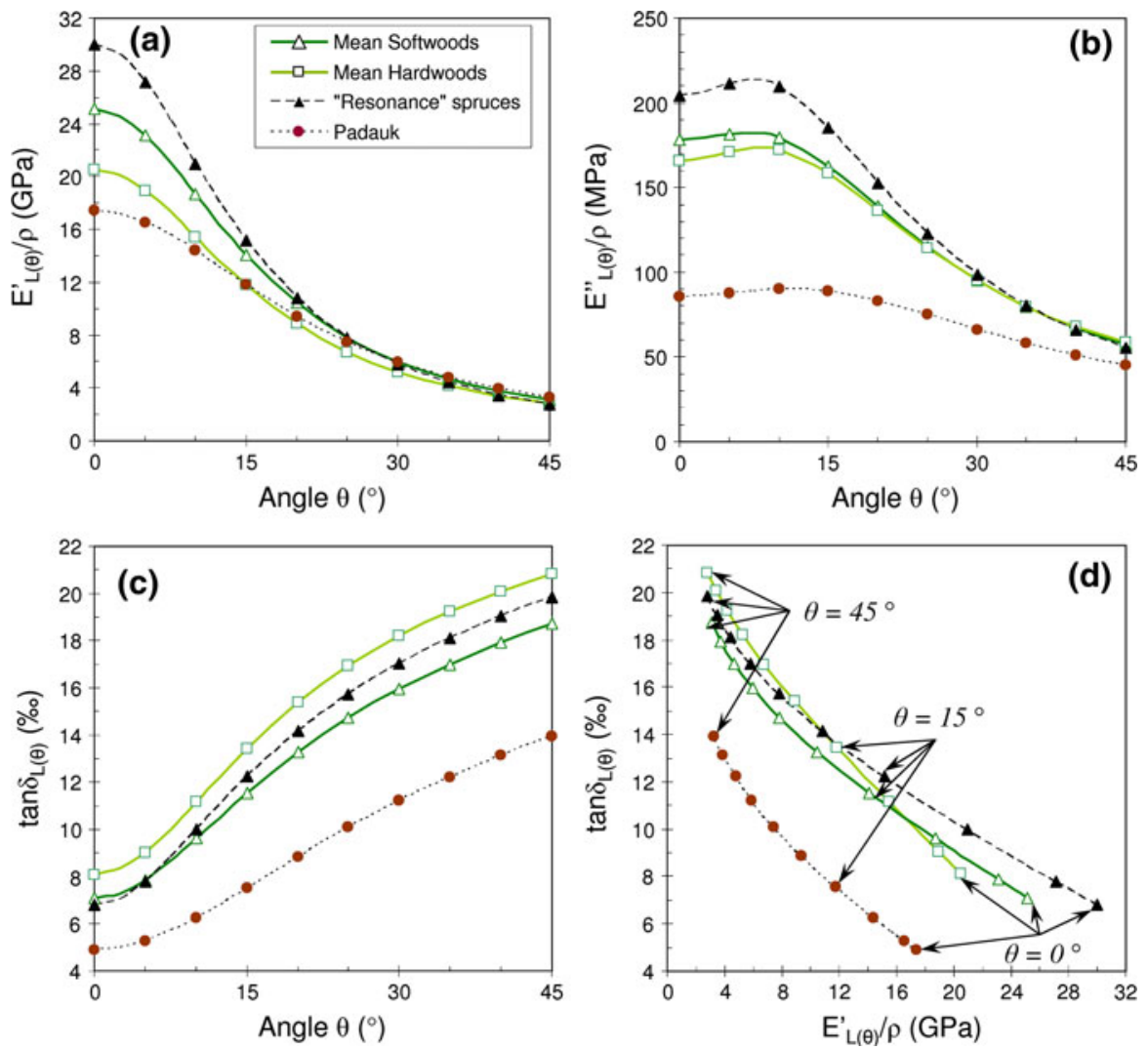

Fig. 3 Dependence of dynamic mechanical properties on grain angle ( $L-T$ plane) calculated using the sets of parameters from Table 4 for different types of woods. Trends in specific storage modulus (a), specific loss modulus (b) and damping coefficient (c) at the global scale, as a function of grain angle. d Calculated evolution of $\tan \delta$ plotted against that of $E^{\prime} / \rho$

very comparable for mean hardwoods and softwoods and for "resonance" spruce, while that for padauk systematically remains "shifted" downwards low $\tan \delta$ values.

Calculations of GA dependences of vibrational properties are in quite good agreement with published experimental values, as illustrated in Fig. 4 for two contrasted wood types: (1) "resonance" spruce with a high $E_{3}^{\prime} / \rho$, cut every $10^{\circ}$ or $15^{\circ}$ in $L-R$ plane (Ono 1983; Tonosaki et al. 1983). (2) Rio rosewood (Dalbergia nigra) cut every $10^{\circ}$ in $L-T R$ plane (Yano et al. 1995) is compared with calculations based on padauk parameters from Table 4, as both these medium-heavy Leguminosae species have a reduced anisotropy, and abnormally low damping coefficients (due to their particular extractives). The calculations of the authors (using Eqs. 7 and 12) provide good predictions for both "extreme" types of woods, including loss parameters which GA dependence had been hitherto approached either by statistical means or by simplified formulas. 

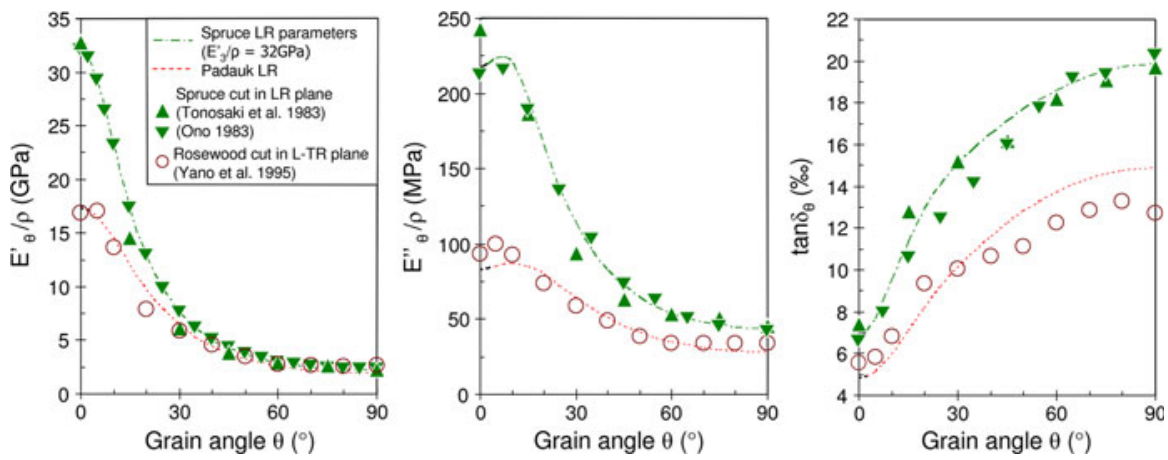

Fig. 4 Comparison of calculated (using Eqs. 7 and 12) and experimentally determined grain-angle dependence for contrasted types of wood. Curves: calculated with $L-R$ anisotropic parameters for spruce (axial $E^{\prime} / \rho$ adjusted to $32 \mathrm{GPa}$ ) and padauk (Table 4). Triangles: Sitka spruce cut at angles in $L-R$ plane (Ono 1983; Tonosaki et al. 1983). Circles: Rio rosewood (Dalbergia nigra) cut at angles in $L-T R$ plane (Yano et al. 1995)

\section{Relationship between damping coefficient and specific storage modulus along with varying grain angle}

In Fig. 3d, it can be noted that calculated GA dependence trends for $\tan \delta$ and $E^{\prime} / \rho$ are related in a way very similar to the relationships proposed by Ono and Norimoto (1983, 1984, 1985). Calculated relations are compared to these statistical regressions (in the form of $\tan \delta=A \times\left[E^{\prime} / \rho\right]^{-\mathrm{B}}$ ) in Fig. 5, where curves (a) and (b) are observed as a function of grain angle, and curves (c) and (d) on wood along the grain, i.e. as a function of microfibril angle. These four regression curves are rather close to each other, suggesting that microfibril- and grain-angle have similar consequences. The calculated curves of this study (for mean hardwoods and softwoods and spruce) are also quite close to each other, and they are in quite good agreement with the regressions over the extreme ranges of GA and of properties, but they are of a less concave form. This is partly because of the concavity of a power curve fitting in itself, but variations in mechanical properties and anisotropic ratios should also modulate the shape of the $\tan \delta-E^{\prime} / \rho$ relation.

If all anisotropic parameters (axial-shear and axial-transverse, for storage moduli and loss coefficients) are made to vary from their minimum to maximum values, while keeping axial properties constant, the $\tan \delta-E^{\prime} / \rho$ relationship increases slower or faster and of course maximum $\tan \delta$ values are different, yet the shape of the relation remains comparable (Fig. 6a). Moreover, as introduced above, anisotropic ratios are correlated to axial mechanical properties (Tables 2 and 3). If axial properties are roughly adjusted to anisotropic ratios, calculations for low- and highanisotropy woods join up into a common trend (Fig. 6b).

This latter analysis implied that all anisotropic ratios tend to increase or decrease together. However, there is little experimental data (obtained on the same samples) concerning the relations between shear- and transverse-anisotropy of damping coefficients. $\tan \delta_{44} / \tan \delta_{33}$ should be primarily affected by cell-wall properties (Aizawa et al. 1998; Obataya et al. 2000) while $\tan \delta_{22} / \tan \delta_{33}$ could presumably be 


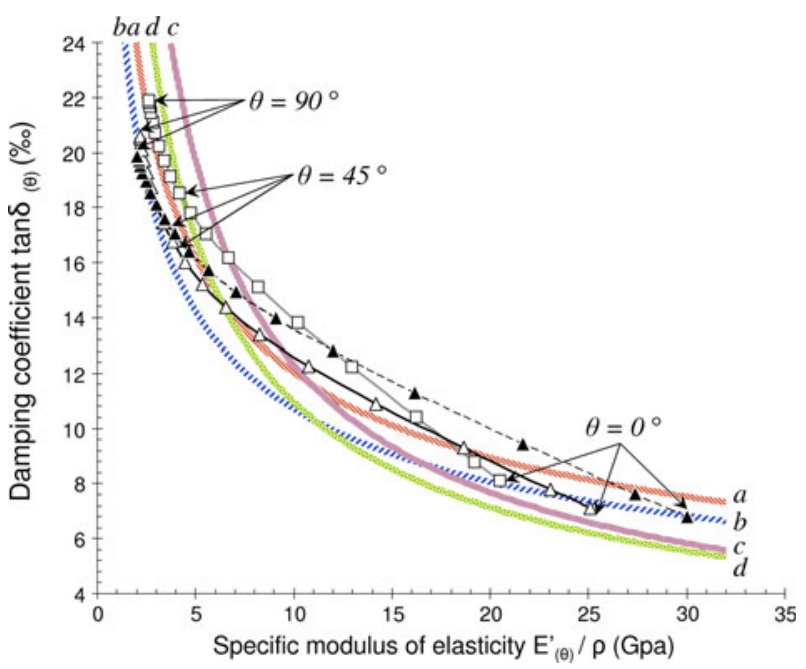

Fig. 5 Comparison of the trends in the damping coefficient-specific modulus relationship: calculated as a function of GA with Eqs. 7-12 and mean anisotropic coefficients (listed in Table 4, symbols: see Fig. 3), and regression curves (thick patterned lines $a, b, c, d$ ) from the literature. ( $a$ ): 5 hardwoods tested along the 3 axes $R, T, L$ at frequencies of 4-20 kHz (Ono and Norimoto 1985); $(b)$ : Sitka spruce with varying GA in $L-R$ plane (Ono and Norimoto 1983); (c) 25 softwood species along the grain (Ono and Norimoto 1983); (d) 30 hardwood species along the grain (Ono and Norimoto 1984)
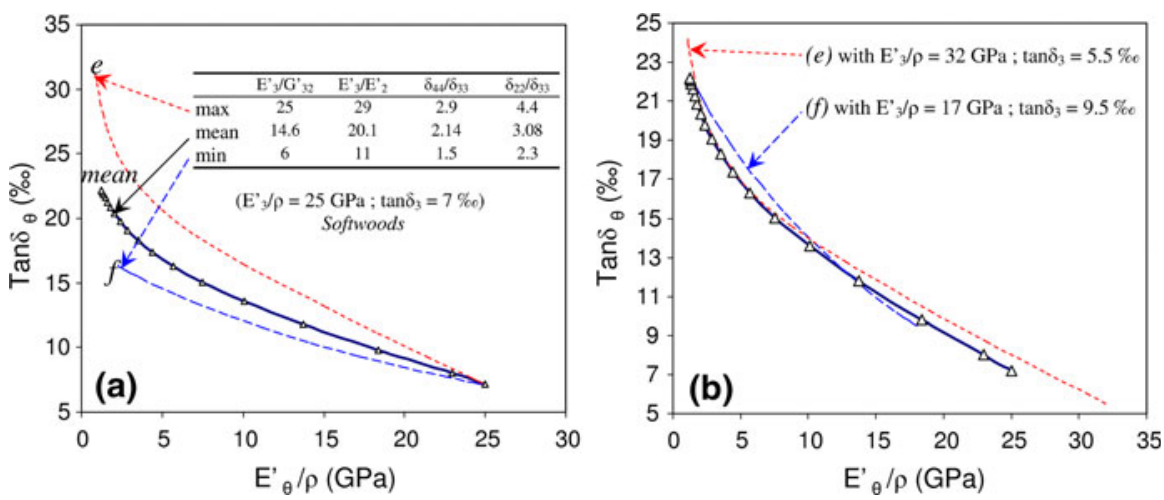

Fig. 6 Variations in the calculated $\tan \delta-E^{\prime} / \rho\left(0^{\circ}-90^{\circ}\right.$ in $L-T$ plane $)$ curve, when varying all anisotropic ratios from their maximum to their minimum. Storage and loss anisotropic ratios are considered as correlated. (a) Properties along the grain are kept constant; (b) $E_{3}^{\prime} / \rho$ and $\tan \delta_{3}$ are adjusted, i.e. they are considered as correlated to anisotropic ratios

more affected by cellular organisation. Varying them separately (Fig. 7) describes as much or even more variability in the $\tan \delta-E^{\prime} / \rho$ relation as total variations in anisotropy do. If $\tan \delta_{44}$ comes close to $\tan \delta_{22}$, the shape of the relation tends towards a linear one. On the contrary, the smaller $\tan \delta_{44} / \tan \delta_{22}$, the more concave the $\tan \delta-E^{\prime} / \rho$ curve. Altogether, variations in damping anisotropic ratios define a plausible range of variation centred on the mean relationship. 


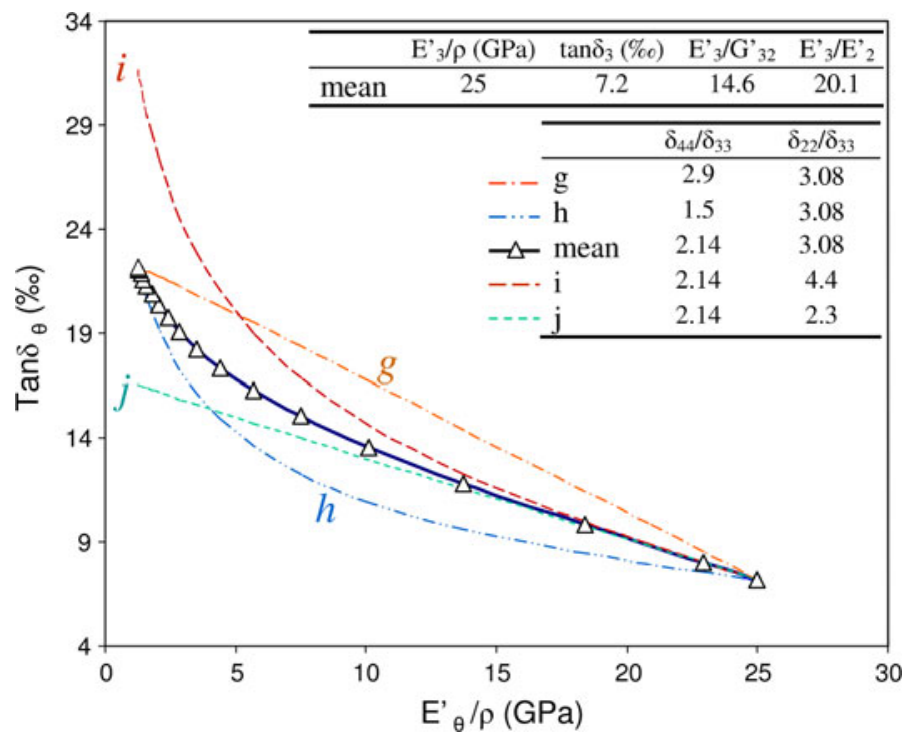

Fig. 7 Variations in the calculated $\tan \delta-E^{\prime} / \rho\left(0^{\circ}-90^{\circ}\right.$ in $L-T$ plane $)$ curve, when varying loss anisotropic ratios (axial-to-shear and axial-tangential) from their maximum to their minimum, while keeping elastic anisotropic ratios and axial properties at their mean values

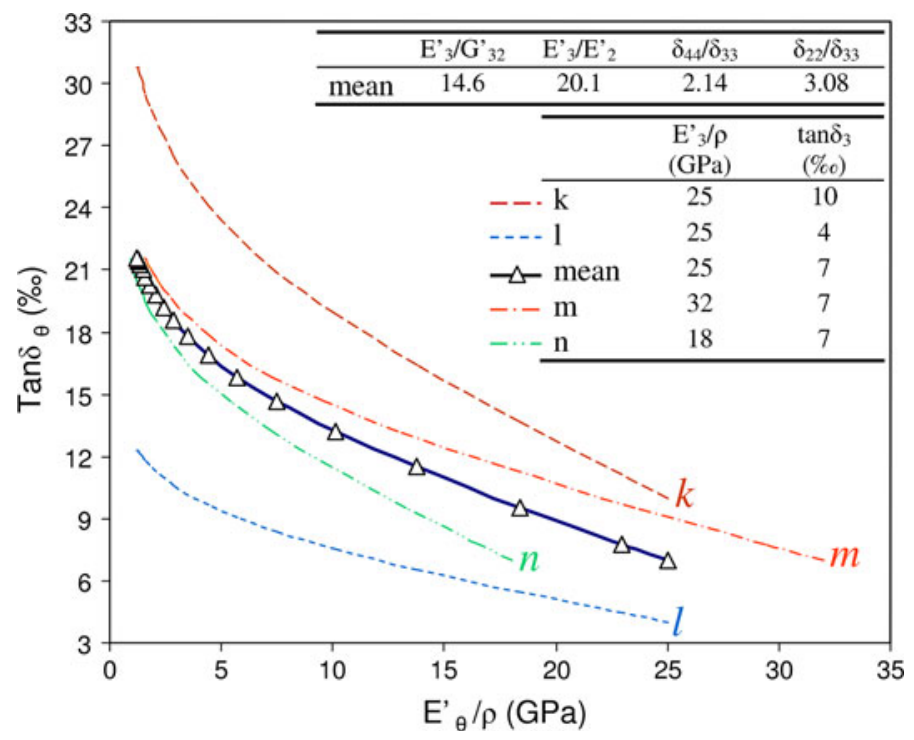

Fig. 8 Variations in the calculated $\tan \delta-E^{\prime} / \rho\left(0^{\circ}-90^{\circ}\right.$ in $L-T$ plane $)$ curve, when varying individually either $\tan \delta$ or $E^{\prime} / \rho$ along the grain, while keeping all anisotropic parameters at their mean values

Finally, if anisotropic parameters are kept constant, and only the axial specific modulus varies, a deviation (from the curve calculated with all mean parameters) is observed over small GA, but trends merge again for increasing grain angles (Fig. 8). 
While variations in axial damping coefficient alone, all else being equal, result in $\tan \delta-E^{\prime} / \rho$ curves that remain shifted towards lower- or higher-tan $\delta$ values, over the whole range of grain angle. This can describe the case of chemical modifications affecting mostly $\tan \delta$, such as for some extractives: parallel but shifted curves are observed either between different species, as was illustrated above for padauk and rosewood, or between sapwood and heartwood of the same species (Brémaud et al. 2010a; Matsunaga et al. 1996; Yano 1994; Yano et al. 1990). Analyses on this topic should however be a bit more detailed, as chemical modifications can also have a smaller but non-negligible effect on $E^{\prime} / \rho$ and elastic anisotropy (Minato et al. 2010; Obataya et al. 2000; Yano et al. 1995).

\section{Conclusion}

This article aimed at evaluating the variability in the anisotropy of wood vibrational properties, and its consequences on their grain angle dependence. The combination of a theoretical mechanical analysis and a review of literature data on anisotropy of dynamic properties has allowed to summarise the following points:

- Axial-to-shear anisotropy in damping (or loss) coefficients ( $\tan \delta$ ) ranges from 1.3 to 3.9 for hardwoods and from 1.4 to 3.3 for softwoods. Axial-to-transverse ratios range from 1.5 to 4.4 and from 2.2 to 4.4 , respectively.

- The anisotropy in $\tan \delta$ is correlated to that in specific elastic moduli. Anisotropic ratios are also positively correlated to axial $E^{\prime} / \rho$.

- Calculations based on transformation formula applied to complex compliances are in good agreement with published experimental data. They efficiently represent the GA dependence both for storage modulus and loss properties, and allow predicting the practical repercussions of GA occurrence in pieces of different types of wood.

- Calculated trends in $\tan \delta$ and in $E^{\prime} / \rho$ allow reconstructing the general relation between these two properties that had been previously reported by statistical means. However, they lead to a less concave curve than the reported power fit. The more or less concave shape of this $\tan \delta-E^{\prime} / \rho$ relation mainly depends on the ratio between shear and transverse damping coefficients.

- The $\tan \delta-E^{\prime} / \rho$ relation for woods with different mechanical parameters is distributed along a unique curve if all anisotropic ratios evolve in conjunction together and with axial $E^{\prime} / \rho$ and $\tan \delta$. On the contrary, variations in $\tan \delta_{33}$ independently of $E_{3}^{\prime} / \rho$ result in parallel curves whatever the orientation be, which coincide with experimental observations on chemically modified woods (artificially or by natural extractives).

The theoretical GA dependence of vibrational properties that was applied here in the simpler case of constant, homogeneous GA, could also serve as the basis for studying more complex phenomena, such as the repercussions of interlocked or wavy grain. In addition, compiled data on anisotropy of dynamic mechanical properties could also be useful for other types of analysis, such as for modelling the vibrational behaviour of beams and plates. 


\section{References}

Aizawa H (1998) Frequency dependence of vibrational properties of wood in longitudinal direction. Master Thesis. Kyoto University (in Japanese)

Aizawa H, Obataya E, Ono T, Norimoto M (1998) Acoutic converting efficiency and anisotropic nature of wood. Wood Res 85:81-83

Aoki T, Yamada T (1972) The viscoelastic properties of wood used for the musical instruments I. Wood Res 52:13-42

Barducci I, Pasqualini G (1948) Measurement of internal friction and elastic constants of wood (in Italian). Il Nuovo Cimento 5:416-466

Bodig J, Jayne BA (1982) Mechanics of wood and wood composites. Van Nostrand Reinhold Company, New York

Brémaud I, Amusant N, Minato K, Gril J, Thibaut B (2010a) Effect of extractives on vibrational properties of African Padauk (Pterocarpus soyauxii Taub.). Wood Sci Technol doi:10.1007/ s00226-010-0337-3

Brémaud I, Cabrolier P, Gril J, Clair B, Gérard J, Minato K, Thibaut B (2010b) b) Identification of anisotropic vibrational properties of Padauk wood with interlocked grain. Wood Sci Technol 44(3):355-367

Bucur V (2006) Acoustics of wood. Springer-Verlag, Berlin, Heidelberg, New York

Caldersmith G, Freeman E (1990) Wood properties from sample plate measurements I. J Catgut Acoust Soc 1(series II):8-12

Green DW, Winandy JE, Kretschmann DE (1999) Mechanical Properties of Wood. Wood handbookWood as an engineering material. Forest Products Laboratory, Madison, WI, USA, p 463

Guitard D, El Amri F (1987) Predictive models of tridimensional elastic behaviour for hardwoods and softwoods. Ann Sci For 44:335-348 (in French)

Haines DW (2000) The essential mechanical properties of wood prepared for musical instruments. Catgut Acoust Soc J 4(series II):20-32

Harris JM (1989) Spiral grain and wave phenomena in wood formation. Springer, Berlin

Ishihara K, Sobue N, Takemura T (1978) Effect of grain angle on complex Young's modulus E* of Spruce and Hoo. Mokuzai gakkaishi 24:375-379

Matsunaga M, Sugiyama M, Minato K, Norimoto M (1996) Physical and mechanical properties required for violin bow materials. Holzforschung 50:511-517

Minato K, Konaka Y, Brémaud I, Suzuki S, Obataya E (2010) Extractives of muirapiranga (Brosimun sp.) and its effects on the vibrational properties of wood. J Wood Sci 56:41-46

Norimoto M, Tanaka F, Ohogama T, Ikimune R (1986) Specific Dynamic Young's Modulus and Internal Friction of Wood in the Longitudinal direction. Wood Res Techn Notes 22:53-65 (in Japanese)

Obataya E (1999) Suitability of acetylated woods for clarinet reed. J Wood Sci 45:106-112

Obataya E, Ono T, Norimoto M (2000) Vibrational properties of wood along the grain. J Mater Sci 35:2993-3001

Obataya E, Ohno Y, Norimoto M, Tomita B (2001) Effects of oriental lacquer (urushi) coating on the vibrational properties of wood used for the soundboards of musical instruments. Acoust Sci Tech $22: 27-34$

Okano T (1991) Acoustic properties of wood. Mokuzai gakkaishi 37:991-998 (Review)

Ono T (1980) The dynamic rigidity modulus and internal friction of several woods in torsional vibration. Mokuzai gakkaishi 26:139-145

Ono T (1983) Effect of grain angle on dynamic mechanical properties of wood. J Soc Mater Sci Jpn 32:108-113

Ono $\mathrm{T}$ (1996) Frequency responses of wood for musical instruments in relation to the vibrational properties. J Acoust Soc Jpn 17:183-193

Ono T, Norimoto M (1983) Study on Young's modulus and internal friction of wood in relation to the evaluation of wood for musical instruments. Jpn J Appl Phys 22:611-614

Ono T, Norimoto M (1984) On physical criteria for the selection of wood for soundboards of musical instruments. Rheol Acta 23:652-656

Ono T, Norimoto M (1985) Anisotropy of dynamic Young's Modulus and internal fricton in wood. Jpn J Appl Phys 24:960-964

Pritz T (2007) The Poisson's loss factor of solid viscoelastic materials. J Sound Vib 306:790-802 
Schniewind AP, Barrett JD (1972) Wood as a linear orthotropic viscoelastic material. Wood Sci Tech 6:43-57

Tonosaki M, Okano T, Asano I (1983) Vibrational properties of Sitka Spruce with longitudinal vibration and flexural vibration. Mokuzai gakkaishi 29:547-552

Yano H (1994) The changes in the acoustic properties of Western Red Cedar due to methanol extraction. Holzforschung 48:491-495

Yano H, Yamada T (1985) The dynamic mechanical properties of wood in the radial direction. Mokuzai gakkaishi 31:222-230

Yano H, Oonishi K, Mukudai J (1990) Acoustic properties of wood for the top plate of guitar. J Soc Mater Sci Jpn 39:1207-1212

Yano H, Matsuoka I, Mukudai J (1992) Acoustic properties of wood for violins. Mokuzai gakkaishi 38:122-127

Yano H, Kyou K, Furuta Y, Kajita H (1995) Acoustic properties of Brazilian rosewood used for guitar back plate. Mokuzai gakkaishi 41:17-22 